\title{
Alimentos funcionais: uma nova fronteira para o desenvolvimento de bebidas protéicas a base de soro de leite
}

\section{Functional Foods: a new frontier for developing whey based protein beverages}

\author{
Ana Carolina Baldissera'; Fabiana Della Betta ${ }^{1}$; Ana Lúcia Barretto Penna ${ }^{2}$; Juliano \\ De Dea Lindner ${ }^{3 *}$
}

\begin{abstract}
Resumo
Alimentos funcionais são definidos como aqueles que fornecem benefícios adicionais aos da alimentação. O mercado de alimentos com propriedades funcionais está em crescente expansão, apoiado por evidências científicas, que creditam o desenvolvimento de alimentos diferenciados. Esse segmento está relacionado às inovações, pois além dos tradicionais produtos funcionais lácteos e não lácteos, ganham espaço no mercado produtos inovadores como bebidas especiais para esportistas a base de soro de leite. Além da funcionalidade sobre a síntese protéica muscular, estas bebidas protéicas estão se inserindo em áreas como a da saciedade e da nutrição clínica. Assim, é possível afirmar que o soro de leite se diferencia como ingrediente de inovação em alimentos e bebidas, porque demonstra uma grande versatilidade tecnológica. Esta revisão objetiva fornecer uma visão geral sobre alimentos funcionais, enfatizando o segmento de bebidas a base de soro de leite. O sucesso desta nova abordagem nutricional está intimamente ligado à necessidade de identificar, caracterizar e desenvolver metodologias para medir e validar com maior precisão os relevantes marcadores funcionais, tornando-os de domínio público, além, é claro, da aceitação por parte do consumidor.
\end{abstract}

Palavras chave: Alimentos funcionais, soro de leite, bebidas protéicas, inovação

\begin{abstract}
Functional foods are defined as those that provide additional benefits to consumers. The market for foods with functional properties is expanding, supported by scientific evidences, which leads the developing of different special foods. This market segment is related to the innovations, as well as the traditional functional dairy and non dairy products, gain traction in the marketplace for innovative products like based whey sports beverage. Besides the functionality of muscle protein synthesis, these beverages are entering into areas such as clinical nutrition and satiety. Thus, it can be supposed that the composition and technological versatility of the whey support the use as innovative ingredient for foods and beverages. This review aim to supply an overview about functional foods, mainly the segment of whey based beverages. The success of this new nutritional approach is close related to the requirement to identify, to characterize and to develop methodologies to measure and to validate more precisely the relevant functional markers, making them open for a public domain.
\end{abstract}

Key words: Functional foods, whey, protein beverages, innovation

\footnotetext{
1 Bolsista de Iniciação Científica. Departamento de Engenharia de Alimentos. Universidade do Estado de Santa Catarina, UDESC. E-mail: anaborella@hotmail.com; fabianadb@gmail.com

2 Prof. do Departamento de Engenharia e Tecnologia de Alimentos, Instituto de Biociências Letras e Ciências Exatas de São José do Rio Preto. Universidade Estadual Paulista Júlio de Mesquita Filho, UNESP. E-mail: analucia@ibilce.unesp.br

3 Departamento de Pesquisa e Desenvolvimento, Incorpore Foods. E-mail: juliano@incorporefoods.com.br

* Autor para correspondência 


\section{Introdução}

Atuais evidências científicas sobre a relação entre a dietaeasaúde, têmlevadoaosurgimentodeummercado de alimentos diferenciados, de rápido crescimento nos últimos anos (ZENITH INTERNATIONAL, 2007). O crescente número de trabalhos científicos publicados nas últimas duas décadas sobre a relação entre dieta e incidência de doenças crônicas, tem destacado o extraordinário potencial dos alimentos para manter ou melhorar o estado de saúde dos consumidores. Como resultado destas evidências científicas, surgiu no Japão na década de 80 os chamados "alimentos funcionais", que consistem na incorporação de determinados ingredientes bioativos, os quais o alimento contêm em pouca quantidade ou não contêm naturalmente (PALANCA et al., 2006). As evidências, primariamente foram sustentadas por estudos realizados com referência aos benefícios à saúde, proporcionados por produtos lácteos, porém o desenvolvimento desta ciência ainda necessita de mais estudos clínicos em humanos em relação a diferentes áreas de atuação funcional (SHORTT; O'BRIEN, 2004).

Alimentos funcionais são definidos como aqueles que fornecem benefícios adicionais aos da alimentação ao consumidor, podendo reduzir o risco de doenças, entretanto não podem ser destinados ao tratamento de doenças agudas ou à utilização de cuidados paliativos (JONES, 2002). Os alimentos funcionais objetivam reforçar a dieta com a ingestão de substâncias cujo efeito salutar não é suficiente através da dieta habitual (PALANCA et al., 2006). Novas tendências alimentares justificam o desenvolvimento de alimentos funcionais, devido a hábitos adquiridos pelas pessoas que tendem a alimentar-se de maneira pouco balanceada e pobre em nutrientes essenciais ao organismo (SALGADO; ALMEIDA, 2009). A sofisticação crescente no mercado de alimentos busca ainda atender demandas dos consumidores, não somente por alimentos convenientes e salutares, mas também por alimentos que aportam uma reivindicação diferente da clássica como, por exemplo, nas bebidas protéicas funcionais a base de soro de leite.
Sustentado pela necessidade do mercado, o desenvolvimento de alimentos funcionais está diretamente unido por três parâmetros: existe uma conscientização por parte dos consumidores sobre o papel positivo ligado a uma dieta com alimentos deste gênero; os órgãos reguladores então cientes a respeito dos benefícios trazidos à saúde pública; em relação ao governo, este está ciente do potencial econômico adquirido por estes produtos.

Um dos segmentos do mercado funcional em potencial desenvolvimento é o de bebidas prontas para o consumo (do inglês RTD: ready to drink). Este foi beneficiado por fatores como o avanço tecnológico na estabilização e utilização de ingredientes como, por exemplo, o soro de leite no caso das bebidas protéicas e das mudanças no estilo de vida. Seguindo tendências européias e norte americanas para o segmento esportivo, as bebidas para esportistas, como por exemplo, ALLPROX®, ISOPURE ${ }^{\circledR}$, MY WHEY ${ }^{\circledR}$, reivindicam aplicabilidade do soro como suplemento, com efeito sobre a síntese protéica músculoesquelética, melhora no desempenho físico, entre outras. Empresas analistas de mercado sustentam um grande potencial de oportunidades para este segmento, com consumidores alvo não somente os adeptos das academias, mas também, idosos, jovens e pacientes nosocomiais com necessidades nutricionais especiais.

\section{Alimentos Funcionais}

Os alimentos funcionais disponíveis atualmente representam apenas uma fração das potenciais oportunidades que consumidores têm de melhorar sua saúde, ingerindo alimentos especiais. Os avanços da ciência, ligados aos estudos dirigidos à área, servem para assegurar que benefícios sejam levados aos consumidores com a adição destes alimentos à dieta diária (CLYDESDALE, 2005).

A literatura referencia alguns critérios estabelecidos para determinação de um alimento funcional, tais como: exercer ação metabólica ou fisiológica, contribuindo para a saúde física e para a diminuição de morbidades crônicas; criar efeitos positivos obtidos 
em quantidades não tóxicas, perdurando mesmo após suspensão de sua ingestão; e, por fim, os alimentos funcionais não são destinados ao tratamento ou cura das doenças (BORGES, 2000).

Um alimento pode ser considerado como funcional, se este demonstrar satisfatoriamente um ou mais efeitos benéficos sobre funções alvo no organismo do consumidor/paciente, além de um adequado efeito nutricional. Efeitos benéficos poderiam ser autorizados para uso com alegação em alimentos funcionais baseados no aumento de um efeito (reivindicação do tipo A) ou redução de risco a patologias (reivindicação do tipo B) (ROBERFROID, 2002b).

Mesmo com o progressivo aumento da popularidade dos alimentos funcionais, nenhuma definição universal para a categoria foi desenvolvida. Nos Estados Unidos da América, a agência FDA (Food and Drug Administration) não fornece uma definição legal para o termo "functional food" e subdivide o termo em duas subcategorias: "Medical Foods" e "Foods for Special Dietary Use". Entretanto, algumas organizações como a ADA (American Dietetic Association), IFIC (International Food Information Council) e o IFT (Institute of Food Technologists) desenvolveram diferentes definições para o termo baseadas, no fornecimento de benefícios salutares adicionais, que podem reduzir o risco de doenças e/ou promoverem uma saúde otimizada. $\mathrm{Na}$ Europa, a "European Commission Concerted Action on Functional Food Science", preconiza que alimentos funcionais além de reduzirem o risco de doenças e/ou promoverem uma saúde otimizada, são ainda alimentos que devem demonstrar os seus efeitos em condições que normalmente seriam esperadas no consumo de uma dieta. O Japão é o único país que reconhece legalmente os alimentos funcionais como uma categoria distinta, favorecendo desta forma o avanço de seu mercado alimentar funcional. Esta categoria legalmente fornece efeitos para determinadas dietas e uso voltado para a manutenção e regulagem de condições de saúde específicas. abordam os aspectos críticos na concepção, desenvolvimento e comercialização de um alimento funcional: identificar o ingrediente com potencial bioativo; avaliar sua eficácia e segurança; selecionarum alimento (veículo) adequado à substância encontrada; regulamentar avaliações sobre a substância; informar os consumidores; fiscalizar o mercado, confirmando as pré-avaliações realizadas.

Demonstrar a eficácia dos componentes dos alimentos funcionais é uma tarefa essencial, principalmente para sua aceitação pelos consumidores, porém é uma trabalho complexo e oneroso. Parâmetros biológicos ou biomarcadores são fundamentais para medir a eficácia dos componentes bioativos, que são encontrados no nosso organismo e servem para comprovar a eficiência do alimento funcional. A Life International Sciences Institute (ILSI, 2002) identificou alguns biomarcadores como demostrado na (Tabela 1).

As últimas tendências, em termos do desenvolvimento de ingredientes funcionais $\mathrm{e}$ oportunidades emergentes no dinâmico segmento comercial de alimentos deste gênero, são sustentadas poravanços tecnológicos e o aumento no conhecimento dos fatores salutares e de envelhecimento da população. A busca por uma diferenciação de mercado inclui o aumento no uso de ingredientes exóticos e inovadores, além da aplicação destes no segmento de sucos e leites. Apesar das consolidadas reivindicações a cerca destes produtos (bom funcionamento intestinal, saúde cardíaca com relação à redução do colesterol, controle de peso e prevenção de carcinomas (ARAI et al., 2002; GONZÁLEZ-GARCÍA, 2002; SCALBERT et al., 2005; GRAJEK; OLEJNIK; SIP, 2005) existem outras ainda pouco exploradas como, por exemplo, a modulação da função imunológica. Desafios a serem superados incluem o estabelecimento de novos nichos, a superação da problemática na obtenção de novos ingredientes em quantidade industrial, e dificuldade com relação a liberação de uso e reivindicação funcional perante os órgãos regulamentadores.

Segundo Clydesdale (2005), alguns passos 
Tabela 1. Biomarcadores de bem estar e redução de risco de doenças ${ }^{\mathrm{a}}$.

\begin{tabular}{ll}
\hline Função & Biomarcador \\
\hline Performance física & Glicogênio no músculo; teste de tempo de resistência. \\
Função intestinal & $\begin{array}{l}\text { Hormônios gastrointestinais (colecisticinina); parâmetros físico/químicos } \\
\text { (viscosidade); respostas fisiológicas/biológicas (tempo de trânsito). } \\
\text { Vários ensaios (como atraso de hiperatividade de reação). }\end{array}$ \\
Função imune & $\begin{array}{l}\text { Redução no consumo de alimentos; redução no consumo de energia; } \\
\text { perfil da taxa metabólica. }\end{array}$ \\
Aterosclerose & $\begin{array}{l}\text { Pressão sanguínea; colesterol LDL; colesterol HDL; espessura média da } \\
\text { túnica íntima da artéria. }\end{array}$ \\
Obesidade & Índice de massa corporal; índice de gordura corporal. \\
Diabetes & Tolerância a glicose; glicemia em jejum; níveis de insulina. \\
Câncer & Pólipos recorrentes no cólon; focos de cripta aberrantes. \\
Saúde dos ossos & Densidade óssea; cinética de cálcio. \\
\hline
\end{tabular}

a - Adaptada de ISLI, 2002.

\section{Características e legislação}

Os alimentos e ingredientes funcionais são classificados quanto à fonte (origem animal ou vegetal) ou quanto aos benefícios que oferecem referentes a seis áreas do organismo (sistema gastrointestinal; sistema cardiovascular; no metabolismo de substratos; no crescimento, desenvolvimento e diferenciação celular; no comportamento das funções fisiológicas e como antioxidantes) (SOUZA; SOUZA NETO; MAIA, 2003).

Segundo a legislação brasileira, alegação de propriedade funcional é aquela relativa ao papel metabólico ou fisiológico que o nutriente ou não nutriente tem no crescimento, desenvolvimento, manutenção e outras funções normais do organismo humano. Não é permitido qualquer tipo de alegação que faça referência à cura ou prevenção de doenças (BRASIL, 1999a, b).

Segundo Roberfroid (2002a, b), os alimentos funcionais apresentam algumas características: devem ser alimentos convencionais, consumidos na dieta normal; devem ser compostos por componentes naturais (em elevada concentração ou presentes em alimentos que naturalmente não o continham); devem ter efeitos positivos, além do valor básico nutritivo, promovendo benefícios à saúde, além de aumentar a qualidade de vida, incluindo desempenho físico, psicológico e comportamental; a alegação de propriedade funcional deve ter embasamento científico; podem ser um alimento no qual a bioatividade de um ou mais componentes tenha sido modificada.

No Brasil, a Agência Nacional de Vigilância Sanitária (ANVISA) regulamentou os alimentos funcionais pela Resolução RDC $n^{\circ} 02$ de 07 de janeiro de 2002, que aprova o regulamento técnico de substâncias bioativas e probióticos isolados com alegação de propriedade funcional ou de saúde (BRASIL, 2002).

Segundo Moraes e Colla (2006), as diretrizes da ANVISA para a utilização da alegação de propriedades funcionais e/ou de saúde são: a alegação é permitida em caráter opcional; o alimento ou ingrediente, além de funções básicas quando se tratar de nutriente pode produzir efeitos metabólicos e/ou fisiológicos e/ou benéficos à saúde, devendo ser seguro sem supervisão médica; para nutrientes com 
funções plenamente reconhecidas pela comunidade científica, não será necessária a demonstração de eficácia ou análise da mesma para alegação funcional na rotulagem; as alegações podem fazer referências à manutenção geral da saúde, ao papel fisiológico dos nutrientes e não nutrientes e à redução de risco de doenças.

\section{Classificações}

Os alimentos funcionais podem assumir diversas tipologias. Alguns podem ser enriquecidos, especialmente criados para reduzir o risco de doença para um determinado grupo de pessoas, outros podem ser alimentos convencionais com componentes bioativos adicionados, que são relacionados com resultados positivos à saúde (CLYDESDALE, 2005), como por exemplo, produtos obtidos pela adição de uma série de ingredientes nutracêuticos, dentre os quais, os ácidos graxos poli-insaturados, antioxidantes, fibras alimentares, fitoesteróis, probióticos, vitaminas, entre outros (FERREIRA; CABRAL; NARDELLI, 2009). Nutracêuticos são substâncias encontradas nos alimentos, que exercem um impacto positivo sobre a saúde humana pela prevenção de doenças ou melhoramento das funções fisiológicas (WILDMAN; KELLEY, 2007).

Entre os diferentes ácidos graxos, alguns podem ser usados como ingredientes funcionais como, por exemplo, o ácido alfa-linolenico (ALA), aracdônico (AA), eicosapentaenoico (EPA), docosanóico (DHA), estearidônico (STA), linoléico conjugado (CLA), entre outros (RUIZ-RODRIGUEZ; REGLERO; IBAÑEZ, 2010). Os ácidos graxos poli-insaturados (PUFA), destacando omega-3 e omega-6, são encontrados em peixes de água fria, óleos vegetais, sementes de linhaça, nozes e alguns vegetais, e considera-se que apresentam efeito de redução da hipercolesterolemia, ação anti-inflamatória, anti-coagulante, vasodilatadora e anti-agregante (RODRÍGUEZ; MEGÍAS; BAENA, 2003; PIMENTEL; FRANCKI; GOLLÜCK, 2005; FERREIRA; CABRAL; NARDELLI, 2009).
Evidências científicas sustentam efeitos benéficos de dietas equilibradas no balanço omega 3/omega 6, suplementadas com antioxidantes (REGLERO et al., 2008).

Um papel importante na avaliação de alimentos funcionais é desempenhado pela biodisponibilidade dos antioxidantes, que é considerado como um fator chave na atividade biológica de substâncias no trato digestivo e sua absorção através das paredes intestinais para a circulação do sangue (GRAJEK; OLEJNIK; SIP, 2005). Antioxidantes são substâncias que retardam a velocidade da oxidação, através de mecanismos como inibição de radicais livres e complexação de metais (PIETTA, 2000). Dentre as substâncias antioxidantes mais destacadas estão as vitaminas C (MARTí et al., 2009) e E (MIYAZAWA et al., 2009), os carotenóides, zinco (PRASAD, 2008; PRASAD et al., 2009), polifenóis, entre outros (CORTÉS; CHIRALT; PUENTE, 2005). Recentemente, a Autoridade Européia para a Segurança Alimentar (EFSA, 2009) declarou através do seu Comitê sobre Produtos Dietéticos, Nutrição e Alergênicos (NDA), que nenhuma evidência foi comprovada em relação aos efeitos benéficos das atividades/conteúdos e/ou propriedades antioxidantes.

Existe um interesse crescente no desenvolvimento e utilização de extratos ricos em polifenóis antioxidantes, como ingredientes funcionais. No entanto, o seu amargor, adstringência e sabor característico poderiam limitar a incorporação em alimentos e bebidas (ARES et al., 2009). Se utilizados em formulações com leite e sacarose, este gosto é mascarado, sendo uma alternativa positiva na incorporação destes em alimentos funcionais a base de leite (DANIELLS, 2009a). Segundo Scalbert, Johnson e Saltmarsh (2005), polifenóis são os mais abundantes antioxidantes incorporados na dieta. Suas maiores fontes são frutas, chás, café e vinho tinto. Vegetais, cereais, chocolates e legumes secos também contribuem para o consumo total de polifenóis. O principal fator de retardo na evolução científica sobre os efeitos dos polifenóis é 
considerado a complexidade e diversidade de suas estruturas químicas. Atuais evidências suportam a contribuição dos polifenóis na prevenção de doenças cardiovasculares (GRASSI et al., 2009), câncer (KOCH et al., 2009) e sugerem um papel na prevenção de doenças neurodegenerativas, diabetes mellitus (SCALBERT et al., 2005) e na proteção do DNA (RAMFUL et al., 2010).

Os carotenóides ( $\beta$-caroteno, $\beta$-cryptoxantina, $\alpha$-caroteno, licopeno, luteína e zeaxantina) estão presentes em alimentos com pigmentação amarela, vermelha ou laranja e fazem parte do sistema de defesa antioxidante em humanos (FERREIRA; CABRAL; NARDELLI, 2009; MAIANI et al., 2009). O $\beta$-caroteno é um potente antioxidante com ação protetora contra doenças cardiovasculares, e tanto os carotenos precursores de vitamina A, quanto os não precursores parecem apresentar ação preventiva contra o câncer, agindo, principalmente, como sequestrante de radicais livres (GRAJEK; OLEJNIK; SIP, 2005; MORAES; COLLA, 2006; DELLA LUCIA et al., 2008).

Os fitoesteróis, possivelmente por apresentarem similaridades estruturais com o colesterol, são capazes de reduzir as taxas de colesterol do sangue, favorecendo uma competição na absorção intestinal e, consequentemente, uma redução nos níveis de colesterol circulante (FERREIRA; CABRAL; NARDELLI, 2009; JONES; ABUMWEIS, 2009). Entretanto este mecanismo não foi completamente elucidado. Estudos conduzidos com $\beta$-sitosterol demonstraram capacidade anti-tumoral especialmente em casos de câncer de cólon, próstata e mama (AWAD; FINK, 2000).

Estudos revelam que alimentos enriquecidos com a vitamina $\mathrm{D}$, tornam-se a melhor opção em alguns países, nos quais o sol é fraco no inverno, impedindo a produção desta vitamina pelo próprio organismo. Esta vitamina tem sido estudada pela sua ação ao reduzir fraturas em até 20 por cento (DANIELLS, 2009b). Vitamina D, através da sua forma ativa, 1,25-dihidroxivitamina $\mathrm{D}$, é essencial para a absorção intestinal do cálcio, manutenção da homeostase cálcica e da saúde do sistema ósseo. Ainda outros efeitos benéficos podem ser associados à suplementação dietética e pela produção dérmica da vitamina D como, por exemplo, a prevenção de doenças auto-imunes, câncer e doenças cardiovasculares (HOLICK, 2004).

As fibras alimentares não são passíveis de hidrólise pelas enzimas do intestino humano, e classificam-se como solúveis e insolúveis, sendo que esta última permanece intacta por todo o trato gastrointestinal, favorecendo o incremento do bolo fecal e a motilidade intestinal, auxiliando no funcionamento do intestino (ROBERFROID, 2002a; MAIHARA et al., 2006; FERREIRA; CABRAL; NARDELLI, 2009). Fibras como a inulina e fruto-oligossacarídeos são reconhecidas como prebióticos com efeitos funcionais em associação a microflora intestinal e com potencial efeito sobre a saúde como, por exemplo, diminuição dos riscos para algumas patologias (infecção intestinal, constipação, obesidade, cancêr de cólon, entre outras) (ROBERFROID, 2002b). Prebióticos são compostos não digeríveis, que afetam beneficamente o hospedeiro, estimulando a proliferação de bactérias desejáveis no cólon como, por exemplo, bactérias ácido lácticas (BAL) probióticas (SAAD, 2006; FARNWORTH, 2001). Estudo recente de Dobbs e Bell (2010), avaliou a estabilidade da tagatose para diversos parâmetros como $\mathrm{pH}$, sistema tampão e temperatura no uso deste monossacarídeo prebiótico em bebidas. Tagatose é reconhecida como uma molécula GRAS (do inglês "Generally Recognized as Safe"), minimamante absorvida na parte superior do trato gastrointestinal, fermentada no intestino a ácidos graxos de cadeia curta (VENEMA; VERMUNT; BRINK, 2005). O consumo da tagatose em alimentos funcionais potencialmente pode conduzir a um aumentar significativo do número de BAL e uma diminuição no número de bactérias do gênero coliformes no intestino (BERTELSEN; JENSEN; BUEMANN, 1999).

Cepas probióticas têm sido amplamente estudadas 
e exploradas comercialmente em diferentes produtos ao redor do mundo (SOCCOL et al., 2010). Segundo a definição atualmente aceita, probióticos são preparações ou produtos contendo microrganismos viáveis, bem definidos e em quantidade suficiente para alterar a microbiota intestinal, quando administrado em quantidade adequada, que conferem benefícios à saúde do hospedeiro (REID et al., 2003; PICARD et al., 2005). Centenas de estudos comprovaram benefícios para a saúde humana e animal, pela ingestão de alimentos e ração probiótica. Na Europa, a EFSA, regulamenta o uso de declarações de efeito sobre a saúde do consumidor e desta forma, a nova normativa (artigo 13.1) que entrou em vigor em meados de 2009, mas ainda não está totalmente implantada, produzirá uma lista de alegações que as indústrias poderão usar em seus produtos funcionais. Alimentos europeus incapazes de provar cientificamente a alegação funcional poderão perder a autorização para serem comercializados. Para os probióticos, até o momento, poucas solicitações de declaração de efeito benéfico foram aprovadas.

Os probióticos mais utilizados envolvem os gêneros Lactobacillus e Bifidobacterium, entretanto leveduras, como o Saccharomyces boulardii, também tem sido utilizadas com potencial probiótico (SZAJEWSKA; MRUKOWICZ, 2005). Para que um microorganismo possa ser empregado como probiótico, vários estudos devem ser conduzidos para a avaliação de sua capacidade de resistência e eficácia (DUNNE et al., 2001; DE DEA LINDNER et al., 2007). Algumas cepas identificadas e testadas como probióticas exibiram potencial anti-inflamatório, anti-alergênico, entre outras importantes propriedades (SOCCOL et al., 2010).

Diferentes matrizes alimentares lácteas e não lácteas têm sido estudadas e usadas como suporte para cepas probióticas, com ou sem o auxílio de tecnologias de microencapsulação, como por exemplo, queijos, sorvetes, sobremesas, leite em pó para neonatos, manteiga, maionese, produtos em pó, cápsulas, vegetais fermentados, sucos de fruta, cereais, entre outras (CHAMPAGNE; GARDNER;
ROY, 2005; SOCCOL et al., 2010). Produtos lácteos, especialmente leites fermentados, estão entre os alimentos com maiores aplicações para estas culturas (ØSTLIE; HELLAND; NARVHUS, 2003; THAMER; PENNA, 2006). Atualmente, produtos à base de soja, com cepas probióticas, têm sido desenvolvidos por serem necessários a pessoas intolerantes à lactose (SALGADO; ALMEIDA, 2009).

\section{Aplicação de soro de leite para alimentos funcionais}

Dentre as mais variadas tipologias de produtos funcionais não lácteos atualmente disponíveis no mercado encontramos: barras de cereais, biscoitos, massas prebióticas, bebidas antioxidantes, chocolates probióticos, entre outros. Entretanto, existe também, uma variada gama de produtos lácteos adicionados de ingredientes que conferem a estes alimentos benefícios à saúde. Destacam-se para o setor lácteo, dentre aqueles com propriedades funcionais comprovadas, os ácidos graxos poli-insaturados, carotenóides, fibras alimentares, fitoesteróis e principalmente os probióticos.

Além dos produtos lácteos serem alimentos nutricionalmente completos, com quantidades importantes de componentes bioativos, estes podem ser potencializados e desta forma atender a crescente necessidade de um público específico, os consumidores de lácteos funcionais.

Bebidas a base de leite e soro de leite, que reivindicam benefícios à saúde, representaram como demonstrado por análises de mercado (NUTRA INGREDIENTS, 2009), serem representantes de mais de $70 \%$ dos lançamentos globais em alimentos funcionais. A maioria das inovações ocorreu na Europa Ocidental (28\%), na Ásia (24\%), seguidas pela América Latina (18\%). Porém, neste cenário de inovação, um declínio nas vendas e lançamentos dos tradicionais iogurtes probióticos pode ser observado, em partes devido à confusão dos consumidores em 
relação às reivindicações salutares. Outros desafios a serem superados incluem facilitar a comprovação de funcionalidade perante os órgãos reguladores (ANVISA, EFSA, FDA, entre outros), disponibilizar de maneira clara e correta a mensagem para o consumidor e identificar novos nichos de mercado territorial (ZENITH INTERNATIONAL, 2009).

Novas oportunidades baseadas em novos efeitos e outras categorias funcionais, como, por exemplo, bebidas para esportistas $\left(\right.$ Boost $\left.^{\circledR}\right)$, bebidas energéticas (Red Bull ${ }^{\circledR}$ ), bebidas calmantes (Slow Cow $^{\circledR}$ ) e cosmecêuticos $\left(\right.$ Innèov $\left.^{\circledR}\right)$, tem ganhado força de mercado e estão direcionando novas pesquisas científicas.

Bebidas lácteas formuladas com mistura de soro de leite e outros produtos lácteos já representam aproximadamente um terço do mercado de leites fermentados. Bebidas a base de leite, soro de leite e frutas, enriquecidas com proteínas estão ganhando espaço, através de um nicho de mercado dominado pela indústria de suplementos protéicos para consumidores que se exercitam com fins de ganho de massa muscular. Além da funcionalidade sobre a síntese protéica muscular, as bebidas protéicas estão inserindo-se em áreas como a da saciedade e nutrição clínica. O desenvolvimento de novas bebidas protéicas prontas para o consumo tem se beneficiado, como todo o mercado funcional, dos avanços tecnológicos no estudo da estabilidade dos componentes, das mudanças no estilo de vida e na melhoria no sabor e textura dos novos produtos.

O consumo por esportistas visando melhoria das aptidões físicas dominou o mercado de bebidas protéicas em um percentual de 45. Produtos com alvo na saciedade ligados ao controle de peso, com suplementação protéica têm sido amplamente estudados e correspondem a $20 \%$ do mercado. Produtos para a nutrição clínica, sucos e bebidas energéticas, respectivamente representam $12 \%, 8 \%$ e $5 \%$ das bebidas protéicas vendidas globalmente durante o ano de 2008 (ZENITH INTERNATIONAL, 2009).
Proveniente da necessidade da indústria de laticínios de desenvolver e usar ingredientes funcionais, o soro de leite demonstra ser uma matéria-prima com grande potencialidade funcional e vantagens comerciais. Porém, a ciência e os avanços tecnológicos, com o intuito de ajudar e definir uma base sólida para uma indústria de reaproveitamento do soro de leite, tem abordado algumas limitações relacionadas ao uso desta matéria-prima, dentre os quais pode-se citar a falta de tecnologias industriais, problemas relacionados à sua estabilidade física e limitações quanto à utilização em alimentos, por ser visto apenas como um produto de baixo valor (SMITHERS, 2008).

O soro de leite é um importante co-produto, gerado pelos laticínios através da caseificação, ou seja, após a coagulação da caseína, variando suas características de acordo com a qualidade do leite e tipologia de processamento (MARSHALL, 2004; SMITHERS, 2008). Atualmente, este é reconhecido como um dos mais versáteis co-produtos da indústria de alimentos e uma fonte útil de proteínas de alta qualidade nutricional e funcional. Devido ao volume produzido e seu alto valor nutricional (aminoácidos essenciais, alto valor de proteínas do complexo B, lactoferrina, $\beta$-lactoglobulina, $\alpha$-lactoalbumina, glicomacropeptideos, imunoglobulinas, e minerais importantes, como o cálcio), empresas que buscam inovação utilizam-se de ingredientes funcionais associados ao uso de soro de leite como matériaprima (MARSHALL, 2004; GLOBALFOOD, 2006; MARRETT, 2009).

O soro de leite, de acordo com o tipo de coagulação sofrida pela caseína na fabricação de queijos, possui duas tipologias: o soro doce, obtido pela coagulação enzimática da caseína, e o soro ácido, obtido pela coagulação por bactérias lácticas ou pela adição direta de ácido mineral ao leite (MUCCHETTI; NEVIANI, 2006). Os principais componentes do soro estão descritos na (Tabela 2). 
Tabela 2. Composição típica do soro doce e ácido .

\begin{tabular}{lcc}
\hline Componentes $(\mathbf{g} / \mathbf{L})$ & Soro Doce & Soro Ácido \\
\hline Sólidos Totais & $63-70$ & $63-70$ \\
Lactose & $46-52$ & $44-46$ \\
Proteína & $6-10$ & $6-8$ \\
Cálcio & $0,4-0,6$ & $1,2-1,6$ \\
Fosfato & $1-3$ & $2-4,5$ \\
Lactato & 2 & 6,4 \\
Cloreto & 1,1 & 1,1 \\
\hline
\end{tabular}

a - Adaptada de Jelen, 2003.

O poder significativamente poluente do soro de leite, com uma DBO cerca de 175 vezes maior do que os típicos efluentes de esgoto, foi em um passado recente, o que levou os governos e outras autoridades reguladoras à restringir e/ou proibir o escoamento do soro de leite não tratado. Mesmo comprovadas as potencialidades do soro como matéria-prima, muitas indústrias ainda o consideram como resíduo e o descartam como um efluente. No Brasil, ainda há resistência no uso do soro na alimentação humana e muitas vezes é utilizado para alimentação animal e/ou adulteração de produtos, ao contrário do que ocorre na Europa e América do Norte.

Dentre as funcionalidades do soro de leite, podese destacar seu poder antioxidante, anti-hipertensivo, antitumoral, hipolipemiante, antiviral, antibacteriano e agente quelante (MARSHALL, 2004; YALCIN, 2006; KRISSANSEN, 2007). Pesquisas indicam que o soro pode ter uma importante contribuição na nutrição esportiva (altos níveis de aminoácidos essenciais), controle do peso corporal (reguladores do metabolismo lipídico), saúde cardíaca e construção óssea (KLEIBEUKER, 2009). Alguns estudos comprovaram que as proteínas do soro são mais rapidamente absorvidas do que outras estudadas, como as proteínas do leite. Por este motivo, pessoas que se submetem a exercícios físicos, quando ingerem destes suplementos, apresentam maior ganho de força e de hipertrofia muscular, por desencadearem a síntese protéica. Estas proteínas também interferem positivamente na redução de gordura corporal em função do seu alto teor de cálcio, melhoram o desempenho muscular por elevar a concentração de glutationa, que é um poderoso antioxidante, ajudam no controle da pressão sanguínea e atuam como agente redutor do risco cardíaco (HARAGUCHI; ABREU; DE PAULA, 2006).

A variedade e funcionalidade das proteínas provenientes do soro permitem a adequação da sua utilização para determinadas aplicações em alimentos. As características funcionais das proteínas estão relacionadas à sua estrutura e função biológica. Segundo Wit (1997), o conceito de propriedades funcionais é freqüentemente utilizado em relação às propriedades físico-químicas da proteína em solução aquosa, porém, seu comportamento funcional em alimentos é mais complexo, variando com alguns fatores. $\mathrm{O}$ desempenho das proteínas do soro em alimentos também pode ser definido como funcionalidade da proteína. Essa característica reflete o modo como as proteínas interagem com os componentes de um produto alimentar (lipídeos, açúcares, sais, e outras proteínas). Essas interações dependem dos efeitos causados pelo processamento (Figura 1). 
Figura 1. Forças condutoras envolvidas nas propriedades funcionais e funcionalidade das proteínas do soro de leite ${ }^{\mathrm{a}}$.

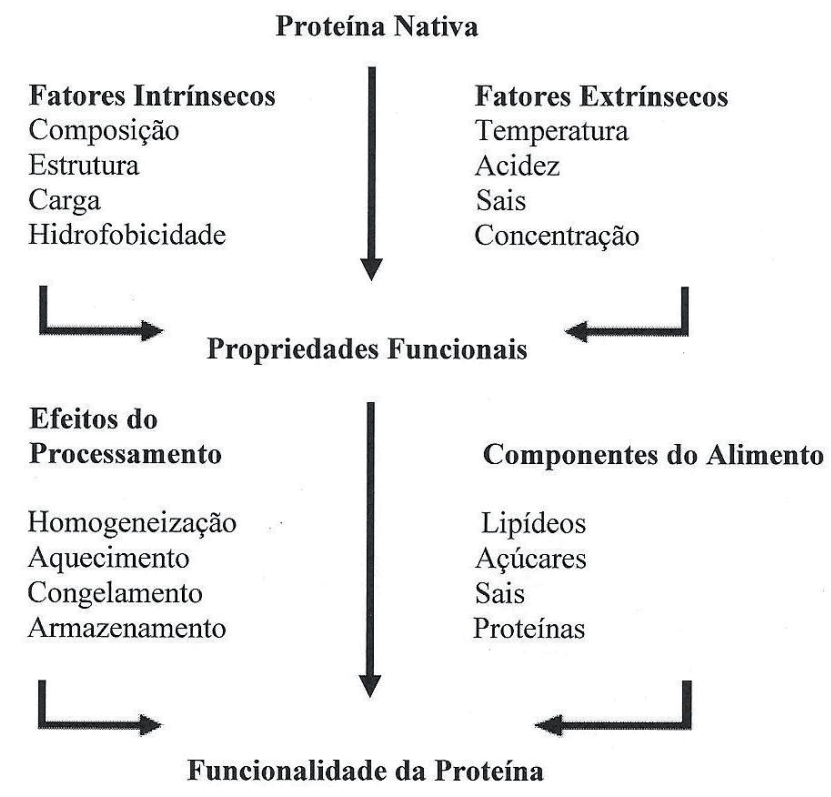

Fonte: ${ }^{\text {a }}$ - Adaptada de Wit, 1997.

O soro se diferencia como um ingrediente de inovação em alimentos e bebidas, porque demonstra umagrandeversatilidade. O soro e consequentemente suas proteínas, podem ser aplicadas como matériaprima multifuncional (propriedades de aeração, emulsificação, gelatinização e alta solubilidade) que fornecem à formulação a capacidade de desenvolver um alimento com apelo no sabor, sensação palatável e aparência. Na grande parte da aplicação como ingrediente, pode ser utilizado na forma líquida ou como concentrado protéico do soro (do inglês "Whey Protein Concentrate" - WPC) ou ainda isolado protéico do soro ("Whey Protein Isolate" - WPI) na forma pulverulenta (KLEIBEUKER, 2009).

Produtos adicionados de soro necessitam de um tratamento térmico para garantir a estabilidade microbiológica do produto. Este tratamento, dependendo da severidade do binômio tempo/ temperatura, pode comportar uma alteração na conformação das proteínas susceptíveis à desnaturação, com perda das propriedades de estabilização da matriz (agregação) e sucessiva coagulação (precipitação), gerando uma solução turva e/ou com precipitado branco. Com o intuito de estabilizar o produto e aumentar a aceitação pelo consumidor, se faz necessário o desenvolvimento de estudos de metodologias. Principalmente três abordagens podem ser executadas para tentar reduzir o dano térmico e desta forma, reduzir a turbidez em bebidas preparadas com a adição de soro de leite ou proteínas concentradas e/ou isoladas: centrifugação (para remover agregados protéicos insolúveis); adição de ingredientes tradicionais e inovadores como, por exemplo, açúcares (frutose e sacarose), edulcorantes de baixa intensidade - poliálcoois (xilitol, sorbitol, manitol e eritritol), aminoácidos (prolina, glutamina e asparagina) e sais (cloreto de sódio, cloreto de cálcio, tiocianato de sódio e sulfato de amônio); alteração do pH (LA CLAIR; ETZEL, 2010). Além de alguns ingredientes químicos que em determinadas concentrações podem prejudicar o gosto da formulação, estudos demonstraram a viabilidade de uso de enzimas fúngicas (peroxidase) que podem clarificar o soro sem criar impropriedades alimentares e desestabilização protéica (HALLIDAY, 2009).

A aceitação do consumidor é um pré-requisito 
para que bebidas protéicas a base de soro entrem com força no pré-existente mercado de bebidas lácteas. Beucler, Drake e Foegeding (2005) formularam uma bebida usando permeado de soro como fonte de eletrólitos e usaram a bebida para testar a aceitação do consumidor e percepção de fatores como a potabilidade, refrescância e propriedades refrigerantes. Bebidas que contém proteínas do soro atualmente são formuladas controlando o $\mathrm{pH}(\leq 3.5)$ com o intuito de manter a limpidez e o aspecto "leve" (BEECHER et al., 2008). Etzel (2004) desenvolveu uma bebida modelo usando WPI com um $\mathrm{pH}$ muito abaixo do ponto isoelétrico (3.0) contendo $25 \mathrm{~g} / \mathrm{L}$ de proteína. A bebida, após tratamento de envase a quente, permaneceu límpida e pode reivindicar a rotulagem como "uma boa fonte de proteína" segundo a normativa 21 CFR101.54 da FDA. A empresa brasileira Incorpore Foods, recentemente desenvolveu um suplemento alimentar proteico (ALLPROX ${ }^{\circledR}$ ) líquido e límpido, pronto para o consumo, com altos teores de proteína isolada do soro de leite (68 g/L), sem adição de conservantes.

Algumas empresas recentemente desenvolveram e estão comercializando sistemas compostos por WPI e WPC adicionados de ingredientes que oferecem máxima funcionalidade protéica para a fabricação de bebidas a baixo $\mathrm{pH}$ com aumento do flavour total. Estes sistemas promovem uma menor necessidade de uso na formulação de ácidos, aromatizantes e adoçantes (DAIRY INDUSTRIES INTERNATIONAL, 2009). Uma bebida protéica pronta para o consumo (POZE®) contendo WPI e chá verde, combinando as propriedades antioxidantes do chá com os benefícios das proteínas na síntese muscular, foi desenvolvida baseada em estudos das reações das proteínas do soro com os fenóis de origem vegetal (RAWEL; KROLL; HOHL, 2001).

\section{Conclusão}

Ingredientes alimentares têm demonstrado um enorme potencial na modulação de algumas funções no organismo e, desta maneira, podem contribuir para a redução do risco de desenvolvimento de algumas patologias. Evidências suportadas por dados científicos, em especial, por testes em vivo, contribuirão cada vez mais para o desenvolvimento da 'ciência dos alimentos funcionais'. Desta forma, convergirão em uma oportunidade única de progresso na regulamentação alimentar que garanta, com validade, tanto as alegações quanto a segurança dos alimentos. Pesquisadores, com os avanços da ciência, têm nas mãos, a possibilidade e oportunidade de correlacionar de forma concreta os benefícios gerados pela ingestão de alimentos funcionais. $O$ sucesso desta nova abordagem nutricional está intimamente ligado à necessidade de identificar, caracterizar e desenvolver metodologias para medir e validar com maior precisão os relevantes marcadores e/ou indicadores funcionais, tornando-os de domínio público.

A viabilidade futura e o sucesso dos alimentos funcionais no mercado, dependem de vários elementos, porém, a questão essencial é a aceitação consciente de consumo de tais produtos. Em mercados saturados como o da Europa e da América do Norte, a batalha por consumidores atualmente se desloca dos clássicos iogurtes probióticos para produtos como, bebidas protéicas e águas funcionais. No Brasil, existe ainda muito espaço para os produtos funcionais clássicos e um mercado totalmente aberto a ser explorado para produtos de inovação.

Indústrias que procuram inovações, cada vez mais tentam utilizar co-produtos e subprodutos, como por exemplo, o soro de leite, para agregarem valor nutricional e funcional e evitarem um maior impacto ambiental na geração de seus resíduos. Uma válida fonte protéica de aproximadamente meio milhão de toneladas de proteínas do soro é subutilizada mundialmente. Propriedades funcionais destas proteínas são reguladas pela composição e estrutura e são influenciadas pelas condições de tratamento e processamento de uso como ingrediente alimentar. Por exemplo, um entendimento a nível molecular na seleção de tratamentos, ingredientes e do $\mathrm{pH}$ 
são fatores necessários para o desenvolvimento de bebidas protéicas estáveis e de boa aceitação visual e sensorial. A desnaturação e a agregação protéica durante a industrialização são, de fato, um dos maiores desafios no desenvolvimento desta nova tipologia de produto funcional.

\section{Agradecimentos}

FAPESC pelo auxílio financeiro (Projeto Ciências Agrárias 008-2009).

\section{Referências}

ARAI, S.; MORINAGA, Y.; YOSHIKAWA, T.; ICHIISHI, E.; KISO, Y.; YAMAZAKI, M.; MOROTOMI, M.; SHIMIZU, M.; KUWATA, T.; KAMINOGAWA, S. Recent trends in functional food science and the industry in Japan. Bioscience, Biotechnology, and Biochemistry, Tokio, v. 66, n. 10, p. 2017-2029, 2002.

ARES, G.; BARREIRO, C.; DELIZA, R.; GAMBARO, A. Alternatives to reduce the bitterness, astringency and characteristic flavour of antioxidant extracts. Food Research International, Rio de Janeiro, v. 42, n. 7, p. 871-878, 2009.

AWAD, A. B.; FINK, C. S. Phytosterols as anticancer dietary components: evidence and mechanism of action. Journal of Nutrition, New York, v. 130, n. 9, p. 21272130, 2000 .

BEECHER, J. W.; DRAKE, M. A.; LUCK, P. J.; FOEGEDING, E. A. Factors regulation astringency of whey protein beverages. Journal of Dairy Science, Madison, v. 91, n. 7, p. 2553-2560, 2008.

BERTELSEN, H.; JENSEN, B. B.; BUEMANN, B. D-Tagatose- a novel low-calorie bulk sweetner with prebiotic properties. World Review of Nutrition and Dietetics, Copenhagen, v. 85, n. 14, p. 98-109, 1999.

BEUCLER, J.; DRAKE, M.; FOEGEDING, E. Design of a beverage from whey permeage. Journal of Dairy Science, Raleigh, v. 70, n. 4, p. 277-285, 2005.

BORGES, V. C. Alimentos funcionais: prebióticos, probióticos, fitoquímicos e simbióticos. In:WAITZBERG, D. L. (Ed.). Nutrição oral, enteral e parenteral na prática clínica. 3. ed. São Paulo: Atheneu. 2000.

BRASIL, Ministério da Saúde. Agência Nacional de Vigilância Sanitária. Resolução n. 18, de 30 de abril de 1999. Aprova o Regulamento Técnico que Estabelece as Diretrizes Básicas para Análise e Comprovação de Propriedades Funcionais e ou de Saúde Alegadas em Rotulagem de Alimentos. Brasília, 1999a.

Resolução n. 19, de 30 de abril de 1999. Aprova o Regulamento Técnico de Procedimentos para Registro de Alimentos com Alegação de Propriedades Funcionais e/ou de Saúde em sua Rotulagem. Brasília, 1999b.

. Resolução n. 2, de 07 de janeiro de 2002. Aprova o Regulamento Técnico de Substâncias Bioativas e Probióticos Isolados com Alegação de Propriedades Funcional e ou de Saúde. Rotulagem. Brasília, 2002.

CHAMPAGNE, C. P.; GARDNER, N. J.; ROY, D. Challenges in the addition of probiotic cultures to foods. Critical Review of Food Science and Nutrition, StHyacinthe, v. 45, n. 1, p. 61-84, 2005.

CLYDESDALE, F. Functional foods: opportunities and challenges. Institute of Food Technologists Expert Report, Washington, p. 1-66, 2005.

CORTÉS, M.; CHIRALT, A.; PUENTE, L. Alimentos funcionales: una historia con mucho presente y futuro. Vitae, Revista de la Facultad de Química Farmacêutica, Medellín, v. 12, n. 1, p. 5-14, 2005.

DAIRY INDUSTRIES INTERNATIONAL. Make whey for way. 2009. Disponível em: <www.dairyindustries. com>. Acesso em: 03 mar. 2010.

DANIELLS, S. Dairy could mask bitter taste of antioxidants. Disponível em: <www.foodnavigator. com>. Acesso em: 15 maio 2009a.

Science supports vitamin $D$ to fewer broken bones. Disponível em: <www.foodnavigator.com>. Acesso em: 25 mar. 2009b.

DE DEA LINDNER, J.; CANCHAYA, C.; ZHANG, Z.; NEVIANI, E.; FITZGERALD, G. F.; SINDEREN, D. V.; VENTURA, M. Exploiting bifidobacterium genomes: the molecular basis of stress response. International Journal of Food Microbiology, Parma, v. 120, n. 1/2, p. 13-24, 2007.

DELLA LUCIA, C. M.; CAMPOS, F. M.; MATA, G. M. S. C.; SANT'ANA, H. M. P. Controle de perdas de carotenóides em hortaliças preparadas em unidade de alimentação e nutrição hospitalar. Ciência Saúde Coletiva, Viçosa, v. 13, n. 5, p. 1627-1636, 2008.

DOBBS, C. M.; BELL, L. N. Storage stability of tagatose in buffer solutions of various compositions. Food Research International, Auburn, v. 43, p. 382-386, 2010.

DUNNE， C.; O'MAHONY, L.; MURPHY, L.; THORNTON, G.; MORRISSEY, D.; O'HALLORAN, S.; FEENEY, M.; FLYNN, S.; FITZGERALD, G.; DALY, C.; KIELY, B.; O’SULLIVAN, G.; SHANAHAN, F.; 
COLLINS, J. K. In vitro selection criteria for probiotic bacteria of human origin: correlation with in vivo findings. American Journal of Clinical Nutrition, Cork, v. 73, n. 2, p. 386-392, 2001.

EUROPEAN SAFETY AUTHORITY - EFSA. Disponível em: <www.efsa.europa.eu/en/ndaclaims/ ndaclaims13.htm>. Acesso em: 25 mar. 2009.

ETZEL, M. Manufacture and use of dairy protein fractions. Journal of Nutricion, Madison, v. 134, n. 4, p. 996-1002, 2004.

FARNWORTH, E. R. Probiotics and prebiotics. In: WILDMAN, R. E. C. (Ed.). Handbook of nutraceuticals and functional foods. 2. ed. Boca Raton, Florida: CRC Press, p. 335-352. 2001.

FERREIRA, E. H. R.; CABRAL, J. R. A.; NARDELLI, P. M. Alimentos funcionais: mercado, regulamentação e benefícios à saúde. Leites e Derivado, São Paulo, n. 113, ano 18, jul. 2009.

GLOBALFOOD. Soro um alimento saudável e base econômica para produtos inovadores. 2006. Disponível em: <http://www.globalfood.com.br>. Acesso em: 22 set. 2009.

GONZÁLEZ-GARCÍA, S. Estudio de la importancia del desarrollo de nuevos productos alimenticios funcionales en Europa. 2002. Tesis (Grado de Master de Diseño Gestión y Desarrollo de Nuevos Productos) - Universidad Politécnica de Valencia España, Valencia.

GRAJEK, W.; OLEJNIK, A.; SIP, A. Probiotics, prebiotics and antioxidants as functional foods. Acta Biochimica Polonica, Poznań, v. 52, n. 3, p. 665-671, 2005.

GRASSI, D.; DESIDERI, G.; CROCE, G.; TIBERTI, S.; AGGIO, A.; FERRI, C. Flavonoids, vascular function and cardiovascular protection. Current Phamaceutical Design, Coppito, v. 15, n. 10, p. 1072-1084, 2009.

HALLIDAY, J. DSM Launches enzymatic whey whitener. 2009. Disponível em: <www.foodnavigator.com>. Acesso em: 30 nov. 2009.

HARAGUCHI, F. K.; ABREU, W. C.; DE PAULA, H. Proteínas do soro do leite: composição, propriedades nutricionais, aplicações no esporte e benefícios para a saúde humana. Revista de Nutrição, Ouro Preto, v. 19, n. 4, p. 479-488, 2006.

HOLICK, M. F. Sunlight and vitamin D for bone health and prevention of autoimmune diseases, cancers and cardiovascular disease. The American Journal of Clinical Nutrition, Boston, v. 80, n. 6, p. 1678-1688, 2004.

ILSI - Life Science International Institute. Functional foods - Scientific and Global Perspectives. ILSI Europe
Series, Summary of a Symposium held in October 2001. Washington, D C: International Life Science Institute Press, p. 7-10, 2002.

JELEN, P. Whey processing - utilization and products. In: ROGINSKI, H. J. W.; FUQUAY; FOX, P. F. (Ed.). Encyclopedia of dairy sciences. London: Academic Press, 2003. p. 2739-2745.

JONES, P. J. Clinical nutrition: 7. Functional foods more than just nutrition. Clinical Basics, Montreal, v. 166, n. 12, p. 1555-1563, 2002.

JONES, P. J. H.; ABUMWEIS, S. S. Phytosterols as functional food ingredients: linkages to cardiovascular disease and cancer. Current Opinion in Clinical Nutrition and Metabolic Care, Winnipeg, v. 12, n. 2, p. 147-151, 2009.

KLEIBEUKER, J. Whey, the way of innovation in the dairy sector. International Dairy Magazine, Madison, v. 9, n. 15, p. 30-31, 2009.

KOCH, T. C.; BRIVIBA, K.; WATZL, B.; FÄHNDRICH, C.; BUB, A.; RECHKEMMER, G.; BARTH, S. W. Prevention of colon carcinogenesis by apple juice in vivo: impact of juice constituents and obesity. Molecular Nutrition \& Food Research, Weinheim, v. 53, n. 10, p. 1289-1302, 2009.

KRISSANSEN, G. W. Emerging health properties of whey proteins and their clinical implications. Journal of the American College of Nutrition, Auckland, v. 26, n. 6, p. 713-723, 2007.

LA CLAIR, C. E.; ETZEL, M. R. Ingredients and $\mathrm{pH}$ are key to clear beverages that contain whey protein. Food Chemistry, Madison, v. 75, n. 1, p. 21-27, 2010.

MAIANI, G.; CASTÓN, M. J. P.; CATASTA, G.; TOTI, E.; CAMBRODÓN, I. G.; BYSTED, A.; GRANADOLORENCIO, F.; OLMEDILLA-ALONSO, B.; KNUTHSEN, P.; VALOTI, M.; BÖHM, V.; MAYERMIEBACH, E.; BEHSNILIAN, D.; SCHLEMMER, U. Carotenoids: actual knowledge on food sources,intakes, stability and bioavailability and their protective role in humans. Molecular Nutrition and Food Research, Weinheim, v. 53, n. 2, p. 194-218, 2009.

MAIHARA, V. A.; SILVA, M. G.; BALDINI, V. L. S.; MIGUEL, A. M. R.; FÁVARO, D. I. T. Avaliação nutricional de dietas de trabalhadores em relação a proteínas, lipídeos, carboidratos, fibras alimentares e vitaminas. Ciência e Tecnologia de Alimentos, São Paulo, v. 26, n. 3, p. 672-677, 2006.

MARRET, N. Manufacturer says refinery tech aids whey process 'purity'. 2009. Disponível em: <www. foodqualitynews.com>. Acesso em: 20 jan. 2010. 
MARSHALL, K. Therapeutic applications of whey protein. Alternative Medicine, Buffalo, v. 9, n. 2, p. 136156, 2004.

MARTÍ, N.; MENA, P.; CÁNOVAS, J. A.; MICOL, V.; SAURA, D. Vitamin $\mathrm{C}$ and the role of citrus juices as functional food. Natural Products Communications, Alicante, v. 4, n. 5, p. 677-700, 2009.

MIYAZAWA, T.; SHIBATA, A.; SOOKWONG, P.; KAWAKAMI, Y.; EITSUKA, T.; ASAI, A.; OIKAWA, S.; NAKAGAWA, K. Antiangiogenic and anticancer potential of unsaturated vitamin E (tocotrienol). Journal of Nutritional Biochemistry, Okayama, v. 20, n. 2, p. 7986, 2009.

MORAES, F. P.; COLLA, L. M. Alimentos funcionais e nutracêuticos: definições, legislação e benefícios à saúde. Revista Eletrônica de Farmácia, Passo Fundo, v. 3, n. 2, p. 109-122, 2006.

MUCCHETTI, G.; NEVIANI, E. Microbiologia $e$ tecnologia lattiero-casearia. Milão: Ed. Tecniche Nuove, 2006.

NUTRA INGREDIENTS. Healthy drinks dominate dairy sector. 2009. Disponível em: <www.mutraingredients. com>. Acesso em: 11 set. 2009.

ØSTLIE, H.; HELLAND, M. H.; NARVHUS, J. Growth and metabolism of probiotics in fermented milk. International Journal of Food Microbiology, Ås, v. 87, n. 1/2, p. 17-27, 2003.

PALANCA, V.; RODRÍGUEZ, E.; SEÑORÁNS, J.; REGLERO, G. Bases científicas para el desarollo de protuctos cárnicos funcionales com actividad biológica combinada. Alimentos funcionales, Nutrición Hospitalaria, Madrid, v. 21, n. 2, p. 199-202, 2006.

PICARD, C.; FIORAMONTI, J.; FRANCOIS, A.; ROBINSON, T.; NEANT, F.; MATUCHANSKY, C. Bifidobacteria as a probiotic agents - physiological effects and clinical benefits. Alimentary Pharmacology \& Therapeutics, Palaiseau, v. 22, n. 6, p. 495-512, 2005.

PIETTA, P. G. Flavonoids as antioxidants. Journal of Natural Products, Segrate, v. 63, n. 7, p. 1035-1042, 2000.

PIMENTEL, B. M. V.; FRANCKI, M.; GOLLÜCKE, B. P. Alimentos funcionais: introdução as principais substâncias bioativas em alimentos. São Paulo: Ed. Varella, 2005.

PRASAD, A. S. Clinical, immunological, antiinflammatory and antioxidant roles of zinc. Experimental Gerontology, Detroid, v. 43, n. 5, p. 370-377, 2008.

PRASAD, A. S.; BECK, F. W. J.; SNELL, D. C.; KUCUK, O. Zinc in cancer prevention. Nutrition and
Cancer, Netherlands, v. 61, n. 6, p. 879-87, 2009.

RAMFUL, D.; BAHORUN, T.; BOURDON, E.; TARNUS, E.; ARUOMA, O. I. Bioactive phenolics and antioxidant propensity of flavedo extracts of Mauritian citrus fruits: potential prophylactic ingredients for functional foods application. Toxicology, Réduit, v. 28, n. 278 , p. $75-87,2010$.

RAWEL, H. M.; KROLL, J.; HOHL, U. C. Model studies on reactions of plants phenols with whey proteins. Nahrung, Bergholz-Rehbrücke, v. 45, n. 2, p. 72-81, 2001.

REGLERO, G.; FRIAL, P.; CIFUENTES, A.; GARCÍA-RISCO, M. R.; JAIME, L.; MARIN, F. R.; PALANCA, V.; RUIZ-RODRÍGUEZ, A.; SANTOYO, S.; SEÑORÁNS, F. J.; SOLER-RIVAS, C.; TORRES, C.; IBAÑEZ, E. Meat-based functional foods for dietary equilibrium omega-6/omega-3. Molecular Nutrition and Food Research, Madrid, v. 52, n. 10, p. 1153-1161, 2008.

REID, G.; SANDERS, M. E.; GASKINS, H. R.; GIBSON, G. R.; MERCENIER, A.; RASTALL, R.; ROBERFROID, M.; ROWLAND, I.; CHERBUT, C.; KLAENHAMMER, T. R. New scientific paradigms for probiotics and prebiotics. Journal of Clinical Gastroenterology, Ontario, v. 37, n. 2, p. 105-118, 2003.

ROBERFROID, M. B. Functional food concept and its application to prebiotics. Digestive and Liver Disease, Louvain, v. 34, n. 2, p. 105-110, 2002a.

. Functional foods: concepts and application to inulin and oligofructose. British Journal of Nutrition, Brussels, v. 87, n. 2, p. 139-143, 2002 b.

RODRÍGUEZ, M. B. S.; MEGÍAS, S. M.; BAENA, B. M. Alimentos funcionales y nutrición óptima. Revista da Espanha de Salut Pública, Madrid, v. 77, n. 3, p. 317331, 2003.

RUIZ-RODRIGUEZ, A.; REGLERO, G.; IBAÑEZ, E. Recent trends in the advanced analysis of bioactive fatty acids. Journal of Pharmaceutical and Biomedical Analysis, Madrid, v. 51, n. 2, p. 305-326, 2010.

SAAD, S. M. I. Probióticos e prebióticos: o estado da arte. Revista Brasileira de Ciências Farmacêuticas, São Paulo, v. 42, n. 1, p. 1-16, 2006.

SAlGADO, J. M.; ALMEIDA, M. A. Mercado de alimentos funcionais: desafios e tendências. Sociedade Brasileira de Alimentos Funcionais (SBAF). 2009. Disponível em: <www.sbaf.org.br/_artigos/200806 Mercado_Alimentos_Funcionais_-_Desafios Tendencias.pdf $>$. Acesso em: 06 nov. 2009.

SCALBERT, A.; JOHNSON, I. T.; SALTMARSH, M. Polyphenols: antioxidants and beyond. The American 
Journal of Clinical Nutrition, Cork, v. 81, n. 1, p. 215217, 2005.

SCALBERT, A.; MANACH, C.; MORAND, C.; RÉMÉSY, C.; JIMÉNEZ, L. Dietary polyphenols and the prevention of diseases. Critical Reviews in Food Science and Nutrition, St-Gèns-Champanelle, v. 45, n. 4, p. 287306, 2005.

SHORTT, C.; O'BRIEN, J. Handbook of functional dairy products. Boca Raton: Ed. CRC, 2004. 314 p.

SMITHERS, G. W. Whey and whey proteins - from 'gutter-to-gold'. International Dairy Journal, Alberta, v. 18, n. 7, p. 695-704, 2008.

SOCCOL, C. R.; VANDENBERGHE, L. P. D. S.; MEDEIROS, A. B. P.; YAMAGUISHI, C. T.; DE DEA LINDNER, J.; PANDEY, A.; THOMAZ-SOCCOL, V. The potential of the probiotics: a review. Food Technology and Biotechnology, Curitiba, v. 48, n. 4, p. 413-434, 2010.

SOUZA, P. H. M.; SOUZA NETO, M. H.; MAIA, G. A. Componentes funcionais nos alimentos. Boletim da SBCTA, Campinas, v. 37, n. 2, p. 127-135, 2003.

SZAJEWSKA, H.; MRUKOWICZ, J. Meta-analysis: non-pathogenic yeast Saccharomices boulardii in the prevention of antibiotic - associated diarrhoea. Alimentary Pharmacology \& Therapeutics, Varsóvia, v. 22, n. 3, p. 365-372, 2005.

THAMER, K. G.; PENNA, A. L. B. Caracterização de bebidas lácteas funcionais fermentadas por probióticos e acrescidas de prebióticos. Ciência e Tecnologia de Alimentos, Campinas, v. 26, n. 3, p. 1-7, 2006.

VENEMA, K.; VERMUNT, S. H. F.; BRINK, E. J. D-Tagatose increases butyrate production by the colonic microbiota in healthy men and women. Microbial Ecology in Health and Disease, Zeist, v. 17, n. 1, p. 4757, 2005.

WILDMAN, R. E. C.; KELLEY, M. Nutraceutical and functional food. In: WILDMAN, R. E. C. (Ed.). Handbook of nutraceuticals and functional foods. 2. ed. Boca Raton, Florida: CRC Press. 2007. p. 1-21.

WIT, J. N. Nutritional and functional characteristics of whey proteins in food products. Journal of Dairy Science, Madison, v. 81, n. 3, p. 597-608, 1997.

YALCIN, A. S. Emerging therapeutic potential of whey proteins and peptides. Current Pharmaceutical Design, Haydarpasa-Istanbul, v. 12, n. 13, p. 1637-1643, 2006.

ZENITH INTERNATIONAL. Functional dairy drinks. 2007. Disponível em: <www.zenith.com>. Acesso em: 23 fev. 2010.
. Global RTD protein drinks. 2009. Disponível em: <www.zenith.com>. Acesso em: 23 fev. 2010. 
